\title{
TRAUMA BONDING: КОНЦЕПЦИИ, ПРИЧИНЫ И МЕХАНИЗМЫ ИНТИМНЫХ ОТНОШЕНИЙ
}

\section{TЕОРЕТИЧЕСКИЙ ТЕСТ}

FONSECA, Nicole de Queiroz Lima ${ }^{1}$, OLIVEIRA, Bruno Quintino de ${ }^{2}$

FONSECA, Nicole de Queiroz Lima. OLIVEIRA, Bruno Quintino de. Trauma bonding: концепции, причины и механизмы интимных отношений. Revista Científica Multidisciplinar Núcleo do Conhecimento. Год. 06, Изготовить. 11, Vol. 06, c. 60-78. Ноябрь 2021 года. ISSN: 2448-0959, Ссылка доступа: https://www.nucleodoconhecimento.com.br/психология/интимных-отношений, DOI: 10.32749/nucleodoconhecimento.com.br/ru/101128

\author{
"Não te quero senão porque te quero \\ e de querer-te a não querer-te chego \\ e de esperar-te quando não te espero \\ passa meu coração do frio ao fogo. \\ Quero-te apenas porque a ti eu quero, \\ a ti odeio sem fim e, odiando-te, te suplico, \\ e a medida do meu amor viajante \\ é não ver-te e amar-te como um ego...”. \\ (PABLO NERUDA - SONETO LXVI).
}

\footnotetext{
${ }^{1}$ Студент факультета психологии. ORCID: 0000-0003-1739-9532

${ }^{2}$ Аспирант по психоаналитической теории - UFRJ, магистр клинической психологии - PUC RJ, специалист по психическому здоровью - HU / UFJF, степень в области психологии - UFF. ORCID: 0000-0002-7956-7899
}

RC: 101128

Доступно в: https://www.nucleodoconhecimento.com.br/психология/интимных- 


\section{СВОДКА}

Когда после инцидента с насилием устанавливаются сильные эмоциональные связи, чтобы связать двух людей, возникает травма, называемая в литературе trauma bonding. Это эмоциональная зависимость между двумя людьми в отношениях, характеризующихся периодами жестокого обращения, насилия и дисбаланса власти, с узами интенсивной связи, когнитивных искажений и поведенческих стратегий обоих людей, которые, как это ни парадоксально, укрепляют и поддерживают связь, что отражено в порочном круге насилия. Однако в Бразилии отсутствует литература и научные исследования по этому вопросу, что подчеркивает необходимость точного и глубокого изучения, поскольку причины и последствия травма связи не совсем ясны, что требует понимания и лечения людей. как и их выздоровление, процесс медленный и болезненный. Таким образом, данное исследование руководствуется вопросом: что такое bonding травма и каковы ее механизмы? Таким образом, общая цель была определена как общая цель анализа bonding травма в романтических отношениях, чтобы пролить свет на нейропсихобиологические процессы травма, возникающей в интимных отношениях, и исследовать причины, по которым жертвы остаются в патологических отношениях. Стокгольмский синдром и посттравматический стрессовое расстройство у жертв жестокого обращения в романтических отношениях как генераторы bonding травма. Для контекстуализации, анализа и проверки теоретической основы, использованной в проведенном исследовании, использовалась методология обзора литературы или библиографического обзора, основанного на чтении, выборе и анализе текстов разных жанров, таких как записи, обзоры и связанные с ними научные статьи к предмету, и которые были опубликованы в журналах и газетах в этом

районе. Был сделан вывод, что несколько эмоциональных и нейропсихобиологических фракторов выступают в качестве причины связующей травма в отношениях.

$\mathrm{RC}: 101128$

Доступно в: https://www.nucleodoconhecimento.com.br/психология/интимных- 
Ключевые слова: Травма, Bonding травма, Посттравматическое стрессовое расстройство, стокгольмский синдром, насилие в интимных отношениях.

\section{1. ВСТУПЛЕНИЕ}

Это исследование направлено на анализ bonding травма в интимных отношениях, в которых существует определенный образец поведения, основанный на жестоком обращении со стороны одного из партнеров. Много говорится о психологическом и сексуальном насилии в афрфективных отношениях и о последствиях, которые они вызывают, однако основные цели этого исследования имеют два различных и взаимосвязанных характера: а) пролить свет на нейропсихобиологические процессы травма, возникающие в интимных отношениях; и б) исследовать причины, по которым жертвы остаются в патологических отношениях.

Отсутствие литературы и научных исследований в этой области в Бразилии выявляет необходимость уточненного и углубленного изучения, поскольку причины и последствия bonding травма все еще не совсем ясны, что делает понимание и лечение людей, а также их выздоровление медленным и болезненным процессом. Жертвы травма должны научиться создавать отношения, которые не основаны на страхе и злоупотреблении властью, даже если такое злоупотребление властью воспринимается как естественное и определенное (BLOOM, 1999).

В здравом смысле широко распространено мнение, что люди, которые остаются в отношениях, считающихся оскорбительными, делают это исключительно по причинам фринансовой и социальной зависимости, низкой самооценки и / или психологической зависимости. Хотя такие аспекты могут быть уместными, исследования показывают, что bonding травма - это то, что на самом деле удерживает субъектов в рискованных ситуациях в их 
романтических отношениях. В своей работе «The Betrayal Bond» Карнес (2019) объясняют, что:

Trauma bonds são formas disfuncionais de ligação que ocorrem na presença de perigo, vergonha e abuso. Esses relacionamentos são bem diferentes das ligações que ocorrem naturalmente quando experimentamos um evento traumático com outras pessoas e 0 resultado geralmente é uma união ou estreitamento de uma ligação como método de sobrevivência. Trauma bonds, por outro lado, acontecem quando nos apegamos à exata pessoa que é a fonte do medo, vergonha e abuso. Este tipo de ligação não facilita a recuperação e resiliência, sabotando tais qualidades em nós, e frequentemente deixam um impacto a longo prazo, geralmente envolvendo sedução e traição[3]. (CARNES, 2019, p. 121).

Traumatic (или травма) bondings создаются, когда устанавливаются сильные эмоциональные связи, чтобы связать двух людей, после инцидента, в котором человек нападает, выражает насильственное поведение, является оскорбительным, пугающим и угрожающим. Это эмоциональная зависимость между двумя людьми, в отношениях, характеризующихся периодами насилия, насилия и дисбаланса сил. Корень этой связи отмечен чувствами интенсивной связи, когнитивными искажениями и поведенческими стратегиями обоих индивидов, которые парадоксальным образом укрепляют и поддерживают связь, что отражается в порочном круге насилия (DEYOUNG; LOWRY, 1992).

С фризиологической точки зрения можно сказать, что человеческий мозг во всей его сложности активируется во время психосоциального процесса создания bonding травма. Такие авторы, как Ван Дер Колк (1989, 1991, 1994, 2001), Симонич и Осевска (2019), Фишер (2010) и Блум (1999) постулируют исследования, которые показывают доказательства того, что люди, которые являются жертвами частого или продолжительного насилия, также как травма в детстве, с большей вероятностью будут вовлечены в отношения со связующей травма из-за механизма вознаграждения в организме, который стремится к повторению определенных ощущений, вызванных выбросом эндорфинов после окончания кризисной ситуации.

$\mathrm{RC}: 101128$

Доступно в: https://www.nucleodoconhecimento.com.br/психология/интимных- 
Второй. Блум (1999) в своей работе «Trauma Theory Abbreviated» этот механизм работает аналогично тому, что происходит в организмах людей, зависимых от наркотических веществ:

[...]essas substâncias mágicas chamadas endorfinas são parte do funcionamento normal e corriqueiro, mas elas são especialmente importantes em momentos de estresse. Novamente, se olharmos para a evolução, faz sentido. Endorfinas não apenas acalmam a ansiedade, melhoram nosso humor e diminuem a agressividade, mas também são ótimos analgésicos já que são relacionados com a morfina e a heroína. Portanto, em tempos de estresse, elas propiciam alívio para a dor o suficiente para que não sejamos incapacitados por ferimentos que poderiam nos impedir de escapar do perigo. Se as pessoas são expostas a raros episódios de intenso estresse, elas possuem menos chances de mostrarem quaisquer mudanças em seu sistema bioquímico. O problema reside nas pessoas que são expostas repetidamente a experiências de estresse prolongado. Tais pessoas, geralmente crianças, são expostas a altos níveis de endorfinas frequentemente. Uma hipótese é a de que os indivíduos podem se tornar 'viciados' em suas próprias endorfinas e, como resultado, só se sentem calmas quando estão sob stress, com medo, irritáveis e hiper excitadas quando o estresse é aliviado, bastante similar a pessoas em abstinência de heroína. Isso é chamado de 'vício em trauma'[4]. (BLOOM, 1999, p. 9).

Несколько гормонов, вырабатываемых в организме человека, участвуют в так называемой «травматической зависимости», которая укрепляет или индуцирует связь с обидчиком, например, окситоцин, который вызывает связи и афффективность; эндогенные опиоиды, отвечающие за удовольствие, боль, воздержание и зависимость; фактор высвобождения кортикотропина, вызывающий воздержание и стресс; дофамин - порождающий тягу, желание, поиск. С таким количеством нейрохимических фракторов в дерегулированных состояниях субъекту чрезвычайно трудно модулировать свои эмоции и принимать решения (BURKETT; YOUNG, 2012).

Другие гормоны влияют на реакцию (или ее отсутствие) у человека перед лицом ситуации насилия и / или постоянства людей в оскорбительных отношениях. Восприятие того, что наказание неизбежно, активирует у субъекта два мозговых механизма: один, который подавляет предыдущее поведение,

RC: 101128

Доступно в: https://www.nucleodoconhecimento.com.br/психология/интимных- 
которое якобы породило причину наказания; и другой, который повышает уровень возбуждения перед лицом создаваемой ситуации насилия. Центральная нервная система в этом случае активирует триггеры для чрезвычайных ситуаций и генерирует поведенческие и когнитивные реакции субъекта, чтобы защитить себя от возможного приступа (BURKETT; YOUNG, 2012).

Несколько исследований показывают, что серотонинергические антагонисты повышают агрессивность в ответ на стресс и гиперреактивность в ответ на раздражители, но подавление поведения, вызванного наказанием, обращается вспять блокаторами серотонина (VAN DER KOLK; SAPORTA, 1991), который выдвигает гипотезу о том, что низкий уровень серотонинергических у жертв травма и посттравматического стресса отвечает за продолжение экстренных реакций на более мелкие раздражители, даже когда причина травма остановлена.

Ван Дер Колк и Сапорта (1991) также объясняют, что тяжесть случаев посттравматического стресса связана с уровнем кортизола в организме субъекта, что подтверждает гипотезу о том, что существует хроническое увеличение кортизола у лиц, страдающих посттравматическим стрессом.

Термин «стокгольмский синдром» был придуман в 1973 году, после ограбления банка в Стокгольме, Швеция, где преступники и заложники оставались в заключении в течение шести дней (MARTIN, 2005). Есть сообщения о том, что за эти шесть дней жертвы развили сочувствие, привязанность и соучастие со своими похитителями. Поскольку было понятно, что это связь между обидчиком и жертвой, такие отношения показались самым внимательным глазам странными, и психиатр и криминолог Нильс Бейерут крестил это явление Стокгольмским синдромом.

$\mathrm{RC}: 101128$

Доступно в: https://www.nucleodoconhecimento.com.br/психология/интимных- 
Исследуя другие переживания на протяжении всей истории психического здоровья на Западе, было замечено, что это явление было особенно распространено в некоторых религиозных культах, в отношениях с возможными военнопленными, в семейных отношениях со случаями детей, ставших жертвами жестокого обращения или инцеста, среди других групп. Также было выявлено, что этот синдром также развивается в любовных отношениях, в которых жертва в конечном итоге создает травматическую связь со своим обидчиком (GEORGE, 2015).

По данным Graham et al. (1995), существует четыре предвестника стокгольмского синдрома: а) опасное для жизни ощущение; б) кажущаяся доброта; в) изоляция; и d) очевидная неспособность избежать ситуации.

Стокгольмский синдром, таким образом, является защитным механизмом для человека, чтобы иметь дело с такими фракторами, которые могут включать когнитивные искажения и восприятие реальности (GEORGE, 2015).

Такие искажения также называются когнитивными диссонансами Леон Фестингер в его работе «A Theory Of Cognitive Dissonance» (1957). Для автора эти диссонансы существуют, когда существует конфлликт или несоответствие между различными убеждениями, или когда субъект сталкивается с информацией, которая опровергает его предыдущие убеждения. Когнитивный диссонанс создает дискомфортное психологическое состояние, которое мотивирует создание мозговых механизмов в виде стратегий уменьшения дискомфорта.

Применяя такую теорию к оскорбительным отношениям, жертва в конечном итоге создает конкретные разработки или даже оправдания для поведения своего партнера, поскольку его основное убеждение заключается в том, что он не подвергается насилию. Даже перед лицом фрактов и доказательств жертва оказывается не в состоянии опровергнуть свой когнитивный диссонанс.

$\mathrm{RC}: 101128$

Доступно в: https://www.nucleodoconhecimento.com.br/психология/интимных- 
Учитывая приведенную выше картину, мы можем понять, что пребывание в оскорбительных отношениях не является чисто психологической или социальной проблемой. Выявление возникновения травма в детстве и на протяжении всей жизни имеет основополагающее значение для понимания того, как неврологические паттерны и травматические связи фрормируются из травма и остаются на протяжении всей жизни (GEORGE, 2015).

Люди, которые подвергаются высокому уровню стресса и кортизола с детства, в результате жестокого обращения с семьей, оставления, инцеста, среди других насильственных ситуаций, в конечном итоге бессознательно ищут или привлекают людей, которые склонны к поведению, считающемся оскорбительным, которое может привести к конфрликту и чувству страха, стыда и насилия, к которым они привыкли, и что их мозг должен модулировать уровни гормонов (BLOOM, 1999).

Психологические и органические реакции, с которыми сталкиваются субъекты, которые в какой-то момент своей жизни решают оставить отношения, считающиеся оскорбительными, аналогичны тем, которые испытывают наркоманы наркотических веществ в воздержании, что дает убедительные признаки наличия механизма, который связывает гормональную продукцию человека с bonding травма (BLOOM, 1999).

В настоящем изложении обосновывается актуальность этого исследования, целью которого является изучение такой динамики, чтобы люди, являющиеся заложниками этих связей, могли фрактически эффеективно оправиться от травм прошлых и настоящих - и, таким образом, предотвратить повторение цикла сам в будущем.

Необходимость углубления понимания понятия bonding травма для приема и лечения индивидов, а также понимания еe биопсихосоциального фрункционирования и краткосрочных и долгосрочных эфрфектов, делают

$\mathrm{RC}: 101128$

Доступно в: https://www.nucleodoconhecimento.com.br/психология/интимных- 
исследования данной темы клиническими, теоретическими, социальными и политическими значениями.

Насилие, фризическое и эмоциональное, в интимных отношениях является всеобъемлющим и вредным явлением, которое происходит во всем обществе, без гендерной дифференциации, затрагивая мужчин, женщин, интерсексуалов и другие гендерные идентичности, что приводит к различным психологическим, социальным и даже фризическим проблемам.

Понимание нейропсихологических аспектов в связывания травма и «травматической зависимости» является задачей первостепенной важности, поскольку из таких компетенций можно будет создавать стратегии клинического вмешательства в этих типах случаев. В качестве начальной точки для будущего построения клинического протокола понимается, что фризиологическая стабильность, согласно Блум (1999), не может быть достигнута, пока человек находится на постоянных американских горках стимулов и реакций.

По этим причинам это исследование направлено на то, чтобы поднять новый взгляд на оскорбительные отношения и постоянство субъектов в этих ситуациях, поскольку отсутствие исследований и научных публикаций в Бразилия может сделать подходы к ситуации устаревшими или устаревшими.

Данное исследование руководствуется следующим руководящим вопросом: что такое bonding травма и каковы ее механизмы? Таким образом, общей целью данной работы является анализ bonding травма в любовных отношениях, с целью рождения нейропсихобиологических процессов травма, порожденных в интимных отношениях, и исследования причин, по которым жертвы остаются в патологических отношениях.В частности, он предназначен для: а) объяснения того, что является bonding травма и как она возникает в оскорбительных отношениях; b) Проанализировать причину, по которой данный профиль жертв насилия остается в этих отношениях; и с) объяснить функционирование

RC: 101128

Доступно в: https://www.nucleodoconhecimento.com.br/психология/интимных- 
стокгольмского синдрома и посттравматического стресса у жертв жестокого обращения в любовных отношениях как фракторов, порождающих bonding травма.

Методология, используемая в этом исследовании, является обзором литературы или обзором литературы. Этот тип методологии имеет своими целями построение контекстуализации проблемы, а также анализ возможностей, присутствующих в литературе, к которым обращаются для концепции теоретической основы исследования.

Для этого были сделаны чтения текстов различных жанров, таких как записи, обзоры и научные статьи, связанные с темой и опубликованные в журналах и газетах в этом районе. Затем был организован и проанализирован материал, собранный библиографической съемкой. Этот анализ способствовал контекстуализации, проблематизации и валидации теоретической основы, используемой в проводимых исследованиях.

\section{2. НАСИЛИЕ И ИНТИМНЫЕ ОТНОШЕНИЯ}

Что заставляет кого-то подвергать насилию человека, которого, по его словам, он любит? Причины могут быть разными, например, злоупотребление психоактивными веществами; предыдущие неврологические состояния, которые могут влиять на поведение; расстройства личности, такие как антисоциальное расстройство личности; Пограничное расстройство личности; и нарциссическое расстройство личности.

Поскольку причины могут быть разнообразными, результат обычно один и тот же: жертва страдает от последствий насилия. Иногда эти партнеры не смогут выйти из таких отношений. Семья, друзья и окружающие этих жертв могут сказать им, чтобы они прекратили отношения и вышли из ситуации страданий,

$\mathrm{RC}: 101128$

Доступно в: https://www.nucleodoconhecimento.com.br/психология/интимных- 
апеллируя к логике; однако естественное функционирование мозга может предотвратить это.

Люди, которые являются жертвами травма, в конечном итоге подвергают себя, по-видимому, навязчиво, ситуациям, которые относятся к первоначальной травме. Это поведение, которое реактивирует травма, редко сознательно понимается как нечто, связанное с переживаниями, которые произошли в начале их жизни. Согласно Ван Дер Колк (1989), люди - это существа, которые полагаются на социальную поддержку, чтобы создать чувство личного смысла, безопасности, власти и контроля. Даже на наше биологическое созревание влияет то, как с детства фрормировались связи. Травма возникает, когда как внутренне, так и внешне субъект не имеет адекватных инструментов для борьбы с внешними угрозами.

Физическая и эмоциональная зрелость, а также врожденные фризиологические изменения в процессе реагирования и восприятия опасности имеют основополагающее значение в способности человека справляться с внешними угрозами. Наличие воспитателей, обеспечивающих безопасность, имеет первостепенное значение для модуляции фризиологического возбуждения у детей, а также их отсутствие может заставить их испытывать взлеты и падения в этом возбуждении, которые являются фризиологически отвратительными и дезорганизующими. Фигура воспитателя, на которого ребенок может рассчитывать в ситуациях, к которым он не готов, имеет основополагающее значение для его развития биологических ресурсов, чтобы противостоять пожизненным угрозам (VAN DER KOLK, 1989).

Согласно Ван Дер Колк (1989), когда люди, которые должны быть источником фризической и эмоциональной защиты и питания, становятся источником опасности, от которой должен быть защищен ребенок, они склонны к регедапту и установлению внутреннего смысла безопасности. Вместо того, чтобы повернуться против своих опекунов и потерять надежду на получение какой-

$\mathrm{RC}: 101128$

Доступно в: https://www.nucleodoconhecimento.com.br/психология/интимных- 
либо защиты, они винят себя и становятся боязливыми, чрезвычайно привязанными, тревожными и послушными.

Уязвимость человека, пострадавшего от травма в начале жизни, делает его склонным к переживанию травма, опять же, во взрослом возрасте, поскольку она становится восприимчивой к такому событию из-за ее измененной когнитивной структуры с детства. Для Ван Дер Колк (1989, стр. 391) «люди, которые подвергаются насилию и пренебрежению в детстве, начинают ждать их как часть жизни[5]». Именно в этом контексте bonding травма становится склонной к оседанию.

Нейробиологические изменения, которые происходят у жертв жестокого обращения, по-видимому, аналогичны изменениям фразы разделения нескорбительных отношений (FISHER et al., 2010). Жертвы насилия в интимных отношениях отличаются от других жертв насилия, потому что они близки к агрессору. Поэтому этот вид насилия сопровождается особой эмоциональной динамикой, основанной на привязанности между жертвой агрессора (SIMONIČ; OSEWSKA, 2019).

Когда кто-то из нас влюбляется и связывается с кем-то новым, нейрохимия системы вознаграждения реагирует, чтобы установить эту связь. В обстоятельствах насилия мозг имеет ту же привязанность, которую любой человек имеет к тому, кого он любит. Однако для жертв насилия любимый человек не в безопасности, а отношения не стабильны (BURKETT; YOUNG, 2012).

То, что происходит нейробиологически в отношениях, состоящих из bonding травма, не сильно отличается от того, что происходит в здоровых отношениях. Основное отличие заключается в том, что, учитывая, что человеческий мозг чрезвычайно чувствителен к происходящему в окружающей среде, он выделяет химические вещества в ответ на оскорбительное поведение партнера. Если он

$\mathrm{RC}: 101128$

Доступно в: https://www.nucleodoconhecimento.com.br/психология/интимных- 
уйдет или будет вести себя агрессивно, в мозге человека с историей травма и который живет оскорбительными отношениями, будет дифференцированная реакция, которую кто-то без истории травма и кто находится в «нормальных отношениях», не будет испытывать. Это также верно в нейрохимии мозга, с эндогенными опиоидами, дофамином и фрактором высвобождения кортикотропина. (BURKETT; YOUNG, 2012).

\section{1 ПОСТТРАВМАТИЧЕСКИЙ СТРЕСС}

Ван Дер Колк (1994) объясняет в своейработе «The Body Keeps Score: Memory and the evolving psychobiology of post-traumatic stress», которая:

O Transtorno de Estresse Pós-Traumático se desenvolve após a exposição a eventos muito angustiantes. O estresse intenso é acompanhado pela liberação de neuro-hormônios endógenos que respondem ao estresse, como cortisol, epinefrina e norepinefrina, vasopressina, ocitocina e opioides endógenos. Esses hormônios ajudam o organismo a mobilizar a energia necessária para lidar com o estresse, desde o aumento da liberação de glicose até o aprimoramento da função imunológica. Em um organismo que funciona bem, o estresse produz respostas hormonais rápidas e pronunciadas. No entanto, o estresse crônico e persistente inibe a eficácia da resposta ao estresse e induz dessensibilização[6]. (VAN DER KOLK, 1994, p. 4).

Посттравматический стресс можно идентифицировать по пяти категориям симптомов: мучительные, повторяющиеся и непроизвольные навязчивые воспоминания о травматическом событии; повторяющиеся тревожные сны, в которых содержание и / или ощущение сновидений связаны с травмирующим событием; диссоциативные реакции (например, flashbacks), при которых человек чувствует или действует так, как будто травматическое событие повторяется снова; сильные или продолжительные психологические страдания из-за воздействия внутренних или внешних знаков, которые символизируют или напоминают какой-либо аспект травмирующего события; интенсивные физиологические реакции на внутренние или внешние сигналы, которые

RC: 101128

Доступно в: https://www.nucleodoconhecimento.com.br/психология/интимных- 
символизируют или напоминают какой-либо аспект травмирующего события (AMERICAN PSYCHIATRIC ASSOCIATION, 2014).

Такие симптомы вызывают высокий уровень замешательства и стресса у выживших, которые не понимают, как они внезапно вышли из-под контроля в своих собственных умах и телах. Неожиданный гнев или слезы, одышка, увеличение частоты сердечных сокращений, тремор, потеря памяти, проблемы с концентрацией внимания, бессонница, ночные кошмары и эмоциональное онемение могут захватить личность и жизнь.

Согласно Ван Дер Колк (2001), после травма человеческий мозг претерпевает биологические изменения, которые он не испытал бы, если бы не произошло травма. Влияние этих изменений особенно усугубляется тремя основными дерегуляциями фрункции мозга:

а) Перевозбужденная миндальня: после травма существует тенденция человека переживать эмоции как фиизиеское состояние, а не словесно закодированные переживания.

б) Уменьшение гиппокампа: увеличение гормона стресса кортизола, токсичного для гиппокампа, заставляет его уменьшаться в размерах, предполагая потерю клеточной массы. Это делает его менее эффективным при создании китатических связей, необходимых для консолидации памяти. Это прерывание стимулирует тело и ум в реактивном режиме, так как ни один из элементов не получает сообщения о том, что угроза изменилась за прошедшее время.

в) Латерализация: Ван Дер Колк (2001) сообщает в своем исследовании, что существует тенденция к латерализации в правом полушарии мозга, ответственном за оценку эмоциональной важности полученной информации и за вегетативную и гормональную регуляцию реакций на эти стимулы. То есть

$\mathrm{RC}: 101128$

Доступно в: https://www.nucleodoconhecimento.com.br/психология/интимных- 
правое полушарие мозга гиперактивировано, и, напротив, область Брока часть левого полушария, отвечающая за перевод личного опыта в вербальное общение - имеет снижение использования кислорода из-за воздействия воспоминаний о травматическом событии.

Учитывая вышесказанное, отмечается, что память о травматическом событии для мозга как будто человек снова переживает ситуацию, и он может видеть, слышать и чувствовать сенсорные элементы, связанные с травма. Существуют также фризиологические нарушения при попытке обнажить травматический опыт с помощью вербальной коммуникации, а также диссоциация чувств (VAN DER KOLK, 2001).

Основываясь на психобиологии травма, отмечается, что функционирование мозга индивида мешает ему воспринимать оскорбительные отношения как таковые, поскольку его мозг и тело привыкли к стрессу и пренебрежению, а также тревоге и страху, которые также вызваны такими отношениями (VAN DER KOLK, 1989).

\section{2 стОКгОЛЬМСКИЙ СИНДРОМ}

Грэм et al. (1995) разработал теорию Стокгольмского синдрома, конкретно связанную с насилием, практикуемым в интимных отношениях, основанную на психологии и поведении таких групп, как члены культа, заключенные концентрационных лагерей, гражданские лица, содержавшиеся в китайских коммунистических тюрьмах, военнопленные, подвергшиеся насилию дети, жертвы инцеста и проститутки, у которых были сутенеры. Она утверждает, что для развития стокгольмского синдрома необходимы четыре предвестника: воспринимаемая угроза выживанию, восприятие доброты, изоляция и восприятие неспособности сбежать.

RC: 101128

Доступно в: https://www.nucleodoconhecimento.com.br/психология/интимных- 
Стокгольмский синдром представляет собой защитный механизм для борьбы с этими фракторами, включая когнитивные и перцептивные искажения. Шестьдесят шесть пунктов были перечислены Грэм (поведение, отношения и убеждения) как связанные с синдромом. Основываясь на этих пунктах, Грэм разработал шкалу из 49 пунктов для измерения стокгольмского синдрома в отношениях (GEORGE, 2015).

В первоначальной шкале Грэм et al. (1995) обнаружил, что предметы были широко представлены тремя категориями: центральный стокгольмский синдром, психологический ущерб и любовная зависимость.

Центральный стокгольмский синдром содержал центральные аспекты теории стокгольмского синдрома и описывал когнитивные искажения и межличностные травма. Они включали в себя рационализацию или минимизацию насильственного поведения партнера, самообоскоряющего поведения перед лицом неудач или поведения партнера и выявление любви в контексте страха.

Психологический ущерб захватил депрессию, низкую самооценку и межличностные трудности.

Любовная зависимость была царит твердой верой в то, что само выживание зависит от привязанности партнера, крайнего идолопоклонства и веры в то, что без партнера не для чего жить (GEORGE, 2015).

Романтическую любовь можно считать зависимостью, так как она демонстрирует характеристики зависимости, такие как: интенсивно сорокусированное внимание субъекта на предпочтительном объекте (в данном случае индивидуальном), внезапные и деконтекстуализированные перепады настроения, интенсивное и неконтролируемое желание, одержимость объектом / индивидуумом, принуждение, искажение реальности, эмоциональная зависимость, изменения личности, принятие высоких рисков для выполнения

$\mathrm{RC}: 101128$

Доступно в: https://www.nucleodoconhecimento.com.br/психология/интимных- 
желаний, связанных с этим объектом / индивидом, и потеря самоконтроля перед лицом собственного желания. Романтическая любовь имеет тенденцию быть конструктивной формой зависимости, когда она отвечает взаимностью, но она может стать разрушительным дополнением, когда ее отвергают (FISHER et al., 2010).

При этой динамике в цикле насилия, любви и отвержения между двумя партнерами создается специфическая фрорма связи, которая в основном основана на эмоциональной динамике и взаимосвязи, при которой жертва, несмотря на свое рациональное признание насилия, глубоко чувствует, что она не способна просто отказаться от жестокого партнера, который, в свою очередь, не меняет вашу модель поведения. Вместо того, чтобы прекратить отношения (и даже если он это делает, возвращается через некоторое время), жертва в конечном итоге укрепляет свою связь с агрессором. Таким образом, сложность оскорбительных отношений углубляется, и цикл насилия повторяется (SIMONIČ; OSEWSKA, 2019).

Дуттон и Паинтер $(1981,1993)$ описали этот тип связи как traumatic bonding, предлагаяболее широкое описание динамики реакции жертвы и преступника с предсказуемыми и непредсказуемыми моделями насилия и реакции на него.

\subsection{BONDING TPABMA}

Bonding травма - это привязанность к оскорбительным отношениям, и ее результатом является травматическая аффективная связь, созданная в цикле насилия, который происходит без вехотного веления человека. Жертвы могут игнорировать тонкие признаки насилия, когда отношения еще ранние и не знают о надвигающемся эмоциональном насилии; однако по мере расширения отношений и углубления связей модель насильственного и оскорбительного поведения одной части отношений имеет тенденцию становиться более ясной (DUTTON; PAINTER, 1993).

$\mathrm{RC}: 101128$

Доступно в: https://www.nucleodoconhecimento.com.br/психология/интимных- 
Как правило, в начале оскорбительных отношений эпизоды жестокого обращения мягкие, а характер насилия все еще неясен. Кроме того, агрессор говорит, что сожалеет и извиняется, а жертва принимает их, что усиливает эмоциональную связь. (DUTTON; PAINTER, 1993). Эта фраза может быть лишь ранней короткой стадией оскорбительных отношений или длиться длительными периодами, пока человек не вступит в новую фазу цикла насилия.

Продолжая отношения оскорбительного характера, траектория цикла насилия следует, и новый этап характеризуется ростом злоупотреблений. Жертва может прийти к мнению, что с ней что-то не так и что она несет ответственность за то, чтобы изменить что-то в себе, что предотвратит насилие. Срабатывают когнитивные реакции, такие как самообвинение, вина, интроекция, передача ответственности за насилие самому себе, а не агрессору, настройка представления событий и даже искаженного самопредставления. Это искаженное представление может временно служить социальным оправданием для борьбы с насилием и рациональным объяснением этого, однако, заставляя жертву продолжать отношения, такая позиция способствует неспособности жертвы окончательно завершить цикл насилия (DUTTON; PAINTER, 1981).

Две характеристики насильственных отношений способствуют формированию травма связи в интимных отношениях: дисбаланс сил и возможная перемежающаяся смешивание насилия или, другими словами, цикл насилия, перемежающийся с фазой «медового месяца». Дисбаланс сил возникает, когда индивид, играющий подчиненную роль, развивает низкую самооценку, снижает свою самоэффрективность и становится более зависимым от жестокого партнера, то есть человека, на котором доминирует (DUTTON; PAINTER, 1993).

Патриархальная социальная структура, характеризующаяся стереотипными гендерными ролями, также может способствовать этому. Если партнер, наблюдал доминирующего положения, жертва оказывается эмоционально и экзистенциально заключенной в тюрьму. Это создает чувство беспомощности в

$\mathrm{RC}: 101128$

Доступно в: https://www.nucleodoconhecimento.com.br/психология/интимныхотношений 
субъекте и усиливает привязанность, потому что жертва, которая видит себя слабой, усваивает негативное восприятие агрессора о нем, делая его еще более зависимым и бессильным, что создает сильную аффективную связь с человеком, который рассматривается как более сильный (SIMONIČ; OSEWSKA, 2019).

Зависимость человека, воспринимаемого как более хрупкая, скрывает, по сути, зависимость и бессилие агрессора, ведь она также зависит от жертвы. По этой причине агрессор временно прерывает насильственное поведение, опасаясь, что перейдет черту и потерпевший покинет его. Тревога, возникающая у агрессора, приводит к поведению умиротворения, с прерыванием фризического и словесного насилия, но обычно все же сохраняющего психологическую манипуляцию. Таким образом, агрессор пытается удержать жертву на своей стороне, когда сталкивается с возможностью быть брошенным. Используя теорию привязанности, которая рассматривает интимные отношения между взрослыми как отношения привязанности, тревога, сопровождающая возможность потери человека, к которому она привязана, является основой таких патологических отношений (DUTTON; WHITE, 2012).

Согласно Джонсону (2008), потребности в привязанности в отношениях здоровы, но в случае оскорбительных отношений проблема возникает, когда такие потребности создаются в контексте неопределенности, порожденной конфликтом. Безопасность отношений помогает людям регулировать свои эмоции, обрабатывать информацию и четко общаться. Те, кто имеет здоровые связи, могут открыто признать свою неуверенность и обратиться к другим за поддержкой, получая прием и адекватный ответ на ситуацию.

Насилие, однако, является дисфункциональным способом оставаться рядом с человеком, за которого оно цепляется, когда пробуждается потребность в связи. Жертва становится тревожной, что затрудняет ей выход из отношений, а

RC: 101128

Доступно в: https://www.nucleodoconhecimento.com.br/психология/интимных- 
также ее агрессору, который желает сохранить контроль над жертвой, чтобы она не бросила его (FINKEL; SLOTTER, 2007).

В этом случае возникает парадокс: насилие усиливает страдания жертвы, желающего сбежать, при этом повышает потребность в связях, которые могли бы регулировать те мучения, которые она ищет в людях, которых считает сильнее себя. Таким образом, агрессор становится источником страха и, в то же время, защиты. Таким образом, травматическая связь является источником травма, а также связью, обеспечивающей безопасность (SIMONIČ; OSEWSKA, 2019).

Аналогичная динамика присутствует при Стокгольмском синдроме, при котором у пострадавшего развивается сильная эмоциональная связь с агрессором. Этот синдром, основанный на когнитивных и восприятии искажениях и привязанности, является в этом контексте защитным механизмом для борьбы с такими фракторами

bonding травма фрормируется и поддерживается тоже из-за особой активности на органическом уровне обоих партнеров в оскорбительных отношениях, характеризующейся дисрегуляцией в секреции дофамина, эндогенных опиоидов, кортикотропина и окситоцина, гормонов, способствующих «травматической зависимости». (BURKETT; YOUNG, 2012).

Окситоцин провоцирует очень мощную неврологическую реакцию, которая способствует созданию связей и построению доверия с партнером. Привязанность и связь между жертвой и агрессором такие же, как и у всех других отношений: усиливаются избытком окситоцина.

Дофрамин стимулирует желание, поиск и семя для другого.

Эндогенные опиоиды связаны с регулированием пропорции удовольствия и боли, воздержания и зависимости.

$\mathrm{RC}: 101128$

Доступно в: https://www.nucleodoconhecimento.com.br/психология/интимных- 
Высвобождение кортикотропина связано с восприятием стрессовых ситуаций и реакций на стресс. При насилии обычно активизируются интенсивные нейрохимические процессы. Проблема в том, что такие нейробиологические процессы, которые активируют привязанность для снятия стресса, протекают в токсических и вредных отношениях, которые также являются источником стресса, что делает эти процессы дерегулированными и заставляет жертву становиться все более зависимой от агрессора, вызывая порочный круг, такой как цикл домашнего насилия (FISHER et al., 2010).

\section{3. ОКОНЧАТЕЛЬНЫЕ СООБРАЖЕНИЯ}

Ввиду вышесказанного, центральный вопрос, сделанный в начале этого исследования об определении bonding травма и о том, какие еe механизмы рассматриваются таким образом, что можно сделать вывод, что несколько эмоциональных и нейропсихобиологических фракторов представлены в качестве причины для bonding травма, которая должна быть установлена в отношениях, и понимание этих переменных становится ффундаментальным, как для терапевтической проработки травматической связи, так и для процесса лечения жертв и изменения их диссонанирующих и вредных паттернов.

Кроме того, известно, что повышенная уязвимость к фрормированию bonding травма в любовных отношениях связана с людьми с историей жестокого обращения и насилия в детстве.

Такие ранние жизненные переживания прерывают естественный процесс создания здоровых связей и изменяют структуру мозга субъекта, вызывая большую восприимчивость к участию в оскорбительных отношениях, как внутренними и гормональными фракторами, так и внешними фракторами, которые дают ему более низкий способ справиться с восприятием опасности и формированием положительных связей; заставляя вас чувствовать себя неспособной выйти из отношений.

$\mathrm{RC}: 101128$

Доступно в: https://www.nucleodoconhecimento.com.br/психология/интимных- 
Межличностные режимы у взрослых людей с историей насилия, как правило, отрицательны и не поддаются тестированию в разных отношениях. Эти схемы могут мотивировать поведение, которое увеличивает вероятность повторной виктимизации.

Таким образом, понятно, что предложенная общая цель: проанализировать bonding травма в романтических отношениях, чтобы пролить свет на нейропсихобиологические процессы травмы, возникающей в интимных отношениях, и исследовать причины, по которым жертвы остаются в патологических отношениях, была явно созерцал.

Более того, учитывая все теоретическое соединение, которое было сделано, считается, что это исследование имеет значительное значение в поднятии некоторых аспектов, связанных с bonding травма, не исчерпывая, однако, тему. Таким образом, предполагается, что эта статья станет основой для дальнейших исследований, которые будут разработаны по этому институту, внося позитивному вкладу в распространение знаний.

\section{ИСПОЛЬЗОВАННАЯ ЛИТЕРАТУРА}

AMERICAN PSYCHIATRIC ASSOCIATION - APA. Manual diagnóstico e estatístico de transtornos mentais: DSM-V. Porto Alegre: Artmed, 2014.

BLOOM, Sandra L. Trauma theory abbreviated. [s.l.: s.n.], 1999. Disponível em: https://strengthcounselling.ca/wp-content/uploads/2018/05/trauma-theoryabbreviated.pdf. Acesso em: 15 abr. 2021.

BURKETT, James P.; YOUNG, Larry J. The behavioral, anatomical and pharmacological parallels between social attachment, love and addiction. Psychopharmacology, v. 224, n. 1, p. 1-26, 2012. Disponível em: https://www.ncbi.nlm.nih.gov/pmc/articles/PMC3469771/. Acesso em: 15 dez. 2020.

RC: 101128

Доступно в: https://www.nucleodoconhecimento.com.br/психология/интимных- 
CARNES, Patrick J. Betrayal Bond: Breaking Free of Exploitive Relationships. [s.I.]: Health Communications, Incorporated, 2019.

DEYOUNG, M.; LOWRY, JA. Traumatic bonding: clinical implications in incest. Child Welfare, 1992 Mar-Apr;71(2):165-175.

DUTTON, Donald; PAINTER, S. L.Traumatic bonding: The development of emotional attachments in battered women and other relationships of intermittent abuse. Victimology, 6, 139-155, 1981.

DUTTON, Donald G.; PAINTER, Susan. Emotional Attachments in Abusive Relationships: A Test of Traumatic Bonding Theory. Violence and Victims. v. 8, $\mathrm{n}$. 2, p. 105-120, 1993.

DUTTON, Donald G.; WHITE, Katherine R. Attachment insecurity and intimate partner violence. Aggression and Violent Behavior, v. 17, n. 5, p. 475-481, 2012.

FESTINGER, Leon. Cognitive Dissonance. Scientific American, v. 207, n. 4, p. 93106, 1962.

FISHER, Helen E.; et al. Reward, Addiction, and Emotion Regulation Systems Associated With Rejection in Love. Journal of Neurophysiology, v. 104, n. 1, p. 5160, 2010.

GEORGE, Vera. Traumatic Bonding and Intimate Partner Violence. [s.I.: s.n.], 2015. Disponível em: https://core.ac.uk/download/pdf/41339659.pdf. Acesso em: 23 Nov. 2020.

GRAHAM, D. L.; RAWLINGS, E. I.; IHMS, K.; LATIMER, D.; FOLIANO, J.; THOMPSON, A.; SUTTMAN, K.; FARRINGTON, M.; HACKER, R. A scale for identifying "Stockholm syndrome" reactions in young dating women: factor structure, reliability, and validity. Violence Vict, 1995 Spring;10(1):3-22. PMID: 8555117.

$\mathrm{RC}: 101128$

Доступно в: https://www.nucleodoconhecimento.com.br/психология/интимных- 
JOHNSON, M. P. A typology of domestic violence: intimate terrorism, violent resistance, and situational couple violence. Boston: Northeastern University Press, 2008.

MARTíN, A. G. As sequelas psicológicas da tortura. Psicologia: Ciência e Profissão [online]. 2005, v. 25, n.3, pp. 434-449. Disponível em: <https://doi.org/10.1590/S1414-98932005000300008>. Acesso em: 22 Ago 2021.

SIMONIČ, Barbara; OSEWSKA, Elzbieta. Traumatic bonding in intimate partner violence: A Relational Family Therapy approach. Family Forum., v. 9, n. 10, 2019. 25167/FF/1092, p. 71-90, 2020.

VAN DER KOLK, Bessel A. The Compulsion to Repeat the Trauma. Psychiatric Clinics of North America, v. 12, n. 2, p. 389-411, 1989.

VAN DER KOLK, B. A. The Body Keeps the Score: Memory and the Evolving Psychobiology of Posttraumatic Stress. Harvard Review of Psychiatry, v. 1, n. 5, p. 253-265, jan. 1994.

VAN DER KOLK, Bessel A.; SAPORTA, Jose. The biological response to psychic trauma: Mechanisms and treatment of intrusion and numbing. Anxiety Research, v. 4, n. 3, p. 199-212, 1991.

VAN DER KOLK, B. A. The psychobiology and psychopharmacology of PTSD. Human Psychopharmacology: Clinical and Experimental, v. 16, n. S1, p. S49-S64, jan. 2001.

\section{ПРИЛОЖЕНИЕ - СПРАВОЧНАЯ СНОСКА}

3. Бесплатный перевод авторов.

4. Бесплатный перевод авторов.

RC: 101128

Доступно в: https://www.nucleodoconhecimento.com.br/психология/интимных- 
5. Бесплатный перевод авторов.

6. Бесплатный перевод авторов.

Представлено: Октябрь 2021 года.

Утвержден: Ноябрь 2021 года.

RC: 101128

Доступно в: https://www.nucleodoconhecimento.com.br/психология/интимныхотношений 